\title{
Influencing Factors and Countermeasures of Scientific Research Ability of Clinical Nursing Staff
}

\author{
ZHANG Zhuo $^{1, \text { a }}$, WANG Xueju ${ }^{2, \text { b }}$, ZHANG Haiyan ${ }^{3, c}$ \\ ${ }^{1}$ Urology Department, China Japan Union Hospital of Jilin University, Changchun City, Jilin \\ Province, China, 130033 \\ 2 Pathology Department, China Japan Union Hospital of Jilin University, Changchun City, Jilin \\ Province, China, 130033 \\ ${ }^{3}$ Gastrointestinal Department, China Japan Union Hospital of Jilin University, Changchun City, \\ Jilin Province, China, 130033 \\ Corresponding Author: ZHANG Haiyan,3455064@qq.com
}

Keywords: Clinical Nurse, Scientific Research Ability, Development Status, Influencing Factors, Promotion Strategy

\begin{abstract}
As an important part of nursing science, nursing science research has been paid more and more attention in recent years and has achieved certain results, which played a great role in promoting the development of nursing. Based on the work experience of the author, this paper firstly analyzed the factors restricting the ability of scientific research and development, and then put forward the strategies to enhance the research capacity of nursing staff. The research results of this paper have some help to figure out the factors influencing the scientific research ability of nursing staff and to make development strategies.
\end{abstract}

\section{Introduction}

The development and progress of any subject can not be separated from scientific research activities, in the same, it is necessary to improve the level of scientific research to maintain the rapid development of nursing and to develop into an independent discipline. Most nurses only carry out scientific research ideas and aspirations, but the number of real scientific research is not much. Most nurses write nursing papers only in the promotion time, which leads to the number of papers is not much, and the quality is not high. The influencing factors of the clinical nurses' scientific research and the promotion strategy are reported as the follows.

\section{Influence Factors}

Overall quality of nursing staff. First, the level of education is low. Since 50s of last century, the nursing education in our country is mainly based on technical secondary school education, and the undergraduate education is restored until 1983. In foreign countries, nursing research is mainly undertaken by the doctor and master's degree, although recovered higher education for more than ten years, but the current nursing team is still secondary school education as the main body. In view of the fact that the education level of the domestic nursing staff is generally low, nursing undergraduate education is bound to become a high level of clinical nursing staff and commitment to the main force of scientific research. Clinical nursing staff lack of scientific research quality 
training, and their knowledge of nursing research is very little. At the same time, there are two kinds of phenomena in clinic, on one hand, a senior clinical nursing staff, clinical experience has rich clinical experience, but they lack scientific knowledge; On the other hand, for the young college graduates, although there is scientific research theory, but they also the lack clinical practice. Thus, it caused that the overall quality of the nursing staff is low. Second, lack of awareness of nursing research. WHO put forward: power, gender and health care institutions are the three main factors influencing the development of nursing major. Most of the people engaged in the nursing profession are female, and the nurse work is ordinary, trivial, so that nursing staff is difficult to go beyond the scope of their work to research, which greatly influenced the professional development. In practice, the nursing staff, regardless of the technical title and the ability to work in the same level are engaged in the same work, which can not be separated from professional and technical level. At the same time, most of the nurses to take care of the work as a career rather than a profession, only consider how to do and rarely consider why to do so, so some nurses lack confidence to engage in scientific research. Third, medical English reading ability is insufficient. At present, the English level of the domestic nursing staff is generally not high, and there are great differences between the regions. In terms of the number of published papers in English, the English level of nursing staff in Beijing, Hubei and Shanghai areas is significantly higher than that in other regions, which may be related to the low level of nursing scientific research and professional English in other areas. The English class the mainly teaches vocabulary, grammar and other public English, from the teaching content to teaching environment, it is lack of medical background, so this learning model leads to most of the nursing staff of professional English level is low, so they can not read English scientific papers easily.

Teaching methods and forms of scientific research. First, the teaching form is single. Nursing research is a very strong practical courses, and the traditional classroom can not effectively stimulate students' imagination and creativity, enthusiasm which greatly constrained the students to create, to suppress the subjectivity, so it is difficult to achieve the best teaching effect. Therefore, the nursing research teaching should be based on classroom teaching, case teaching and writing comments, advocating practical teaching concept and mode. At the same time, the pure theory knowledge teaching often should adopt various forms of teaching, encourage students to fully participate in the teaching, in order to promote the students to learn the enthusiasm and creativity. Second, lack of statistical knowledge. Statistical knowledge is one of the necessary knowledge of nursing research and it runs through the whole process of scientific research, design, data collection, data processing and data analysis. There is a lack of statistical knowledge in the teachers of many nursing colleges, and they can not reasonably merge the knowledge of statistics in the design of scientific research topics. In the nursing research of our country, it is difficult to eliminate the condition of selective bias because of the too small sample size, so it is also one of the key to determine the scientific research results and the quality of the paper to correct the scientific research data. But at present, many published nursing papers rarely used blind spot method to judge the statistical results, and there are varying degrees of defects in some data statistics processing.

Medical literature retrieval ability. Medical literature retrieval mainly includes knowledge and application ability of various medical literature database. The nurse is busy with a lot of treatment and nursing work, rarely reads professional publications, lack of information, and the number of nurses to the library to borrow and browse the information is too small, which largely resulted in the lack of information on the source of the nurses.

Scientific research support fund. Scientific research needs certain financial guarantee. At present, all aspects of society create more conditions and opportunities for medical research, but it 
has not formed a separate reporting channel for nursing scientific research, at the same time, unable to fight for external funding, which has caused some difficulties in the development of nursing research. Nursing research is in the initial stage, regardless of the number and depth of the study, it can not be compared with other areas of research topics, in addition, clinical work is busy, less time for scientific research, more difficulties, lack of scientific research experience are also factors affecting some highly educated nurses engage in nursing research.

\section{Countermeasures}

Establishing and improving the management organization of nursing scientific research. Establishing and improving the management of scientific research management organization, scientific organization and management are the premise of improving the level of nursing research. To establish a perfect the management organization of nursing scientific research, scientific organization and management is the premise to improve the level of nursing scientific research. Focusing on the training of academic leaders, it is the key to improve the level of nursing research. Improving the quality of scientific research of the nurse group, improving the overall scientific research quality of nurses is the basis of improving the level of nursing research. Strengthening the construction of the library, organizing the training of medical literature and network information retrieval skills regularly, timely information is the guarantee of nursing scientific research. To employ some experienced professors as consultants, to take the real scientific research into the daily management.

Strengthening the training of the whole quality of nursing staff. First, enhancing the awareness of nursing staff research. Many nurses believe that scientific research is a difficult task, only those who have obtained a master's degree can understand or engage in nursing research. The cultivation of Undergraduates' scientific research ability has attracted more and more attention of foreign research institutions, for example, to improve the level of undergraduate education, some research universities in the United States carried out a series of reforms, and for the strengthening the cultivation of undergraduate research ability, improving their ability to innovate, training academic reserve personnel has become the center of its reform. The biggest difficulty in carrying out nursing research is the lack of scientific research consciousness, therefore, we should take active measures to enhance the scientific research awareness of nurses and improve their research ability. Second, strengthening the training of foreign language knowledge and statistics. The level of foreign language and knowledge of statistics is the basis of the study of nursing, in order to improve the foreign language, it can send care professional teachers to study abroad, use weekends or holidays for the English training class, encourage nurses to learn English by themselves, and subscribe to the original nursing documents. In statistics, we can schedule a lecture to conduct training according to the current need of statistical knowledge, especially to make the nurse learn to use some statistical software, for example, SPSS statistics software.

Improving teaching methods and increasing the investment in nursing research. From both theoretical and practical, teaching, improving teachers' teaching quality and academic level of scientific research to carry out regular scientific research training, so we can improve the overall quality of students. Case analysis teaching method, evidence-based procedure teaching method, task driven teaching method, simulated situational teaching method and target teaching method are all new teaching method, which can be tried in the daily teaching. In the teaching of nursing research, the combination of multiple teaching methods and traditional classroom teaching can improve the scientific research ability of nursing undergraduates, scientific research level, and establish a rigorous scientific research attitude and scientific research style. The deficiency of scientific 
research funds is an important factor to restrict the development of nursing research, so increasing the investment in nursing research can provide a certain financial support for the development of scientific research. In order to get rid of the current low level and repetitive status quo of nursing scientific research in China, we can set up youth nursing research fund to inspire the enthusiasm of nurses.

\section{Conclusion}

The level of nursing scientific research is one of the main indicators to reflect the nursing level and academic atmosphere of a hospital, so taking effective measures to enhance the research interests of nursing staff has a certain help to create a good scientific research atmosphere. We believe that the clinical nurses' research ability will be greatly improved through the further efforts of the nursing administrators and the further improvement of the nursing education

\section{Reference}

[1] Zhang Yujing. Influencing factors analysis and Countermeasures of scientific research ability of clinical nursing staff [J]. Vocational Technology, 2013,08:62.

[2] Feng Xinwei, Jiao Tong, Sun Yuhong. Analysis on the ability of scientific research of nursing staff in operation room and its influencing factors [J]. Journal of Nursing Management, 2015,10:732-734.

[3] Yang Hongye, Wang Zhiying, Chen Yuanhua. Analysis and Countermeasure of influencing factors of clinical nursing scientific research [J]. Journal of Nursing Education, 2007,07:599-600.

[4] Bi Xingxiu. Investigation on the factors influencing the scientific research ability of nursing staff [J]. Chinese and Foreign Medical Treatment, 2011,24:153.

[5] Zhang Chunfei, Wang Saijun. Factors and Countermeasures of clinical nursing research [J]. Zhejiang Journal of clinical medicine, 2006,04:448. 